\title{
An Innovative Model to Foster Web-based Collaborative Learning
}

\author{
Eugenia M. W. Ng and Ada W. W. Ma \\ The Hong Kong Institute of Education, Hong Kong SAR, China
}

eugenia@ied.edu.hk ama@ied.edu.hk

\begin{abstract}
Learning to learn is the theme of the current educational reform in the Hong Kong Special Administrative Region. Learners should be well equipped with collaborative skills, communication skills, creativity, critical thinking skills, and skills in using information technology to be responsive to the changing requirements of the workplace and the society. We have drawn the elements of collaborative learning from research findings and come up with a new model to be implemented for our learners in the coming semester using the Web as an avenue for on-line discussions and peer assessments. The group projects, biweekly reflective journals, peer assessments should be able to cultivate learners' positive attitude towards sharing. The evidence will be gathered through quantitative and qualitative means to examine if there is any relationship between collaborative learning and peer assessment with the final assessment grades received.
\end{abstract}

Keywords: collaborative learning, model, peer assessment, Web-based learning.

\section{Introduction}

Learning to learn is the theme of the current educational reform in the Hong Kong Special Administrative Region. Collaborative skills, communication skills, creativity, critical thinking skills, skills in using information technology, numeracy skills, problem solving skills, self management skills and study skills are thought to be the essential generic skills to be mastered by learners (Education Commission, 2000). Learners should be well equipped with such transferable skills so that they can be responsive to the changing requirements of the workplace which is dynamic and technology driven. Collaborative learning is one of the many student-centered approaches that matches with the philosophy of contemporary perspectives on learning and teaching aiming to promote higher achievement, more positive interpersonal relationships and greater psychological health, resulting in graduates being cooperative, caring, reflective, critical and creative.

\section{Collaborative Learning}

The concept of collaborative learning has been around a long time. Colonel Francis Paker first introduced the concept of collaborative learning in the American public schools in the late nineteenth century and the concept has further become an active research subject. Over the past three decades, Roger Johnson and

Material published as part of these proceedings, either on-line or in print, is copyrighted by Informing Science. Permission to make digital or paper copy of part or all of these works for personal or classroom use is granted without fee provided that the copies are not made or distributed for profit or commercial advantage AND that copies 1) bear this notice in full and 2) give the full citation on the first page. It is permissible to abstract these works so long as credit is given. To copy in all other cases or to republish or to post on a server or to redistribute to lists requires specific permission from the publisher at Publister@intormingscience.org
David Johnson, two of the most influential advocates of collaborative learning, have put extensive efforts in conducting systematic researches to test theories on collaborative learning and translating the validated theory into a set of concrete strategies and procedures for implementing cooperation in classrooms throughout North America and overseas. Collaborative learning means students working together to accomplish shared learning goals 
and to maximize their own and their group members' achievements (Johnson \& Johnson, 1999).

Since 1898 over 550 experimental and 100 co-relational research studies have been conducted on cooperative, competitive, and individualistic efforts and the results of these theoretical and demonstration studies are highly consistent in supporting the use of cooperative over competitive and individualistic learning (Johnson \& Johnson, 1989). It is suggested that there are clear educational advantages to be derived from collaborative activities among learners, in particular, there are impressive effects across a wide range of ability levels. Johnson \& Norem-Hebeisen (1981) found that cooperativeness was positively related to greater psychological health as working cooperatively with peers cultivated personal ego-strength, selfconfidence, independence, and autonomy. Possessing social skills and having a positive interpersonal relationship is a key to success in one's future career.

Findings of a series of researches supported that social skills and competencies tended to increase more within cooperative situations as working together increased students' abilities to provide leadership, build and maintain trust, communicate effectively and manage conflicts constructively (Johnson \& Johnson, 1989). Research results also indicated that collaborative learning fostered creative thinking as members in a group generated new ideas, strategies, and solutions more frequently than working individually (Johnson \& Johnson, 1989). A study conducted by Slavin (1996) further showed that when students worked in small teams, they were engaged in student-interactions and activities, which frequently required highorder thinking and critical reflections. Johnson \& Johnson (1997) further elaborated that cooperative efforts promoted positive relationships among group members. They had higher morale, were more likely to commit effort to achieve educational goals, were more willing to endure pain and frustration on behalf of learning, as well as to listen to and influenced by classmates and teachers.

In summary, over the past 100 years, the research results consistently indicate that collaborative learning promotes higher achievement, fosters more positive interpersonal relationships and engenders greater psychological health than employing competitive or individualistic learning strategy.

\section{Collaborative Learning via the Web}

The information technology (IT) provides an arena for collaborative learning in a "knowledge-building community" (Scardamalia \& Bereiter, 1994), "a community of practice" (Lave \& Wenger, 1991), "a community of learners" (Brown, 1992), and "a community of reflective practitioners" (Chen, 1993). Among all the IT tools, the Internet is particularly appealing to promote lifelong and life-wide learning as it is abundant, flexible and open. Much of the information on the World Wide Web (hereafter, the Web) could be accessed easily, speedily and freely. The Internet is more than technology and medium. It is a web of social relations imaginatively constructed by symbolic processes initiated and sustained by individuals and groups. The Web-based collaborative learning thus has become very popular in the $21^{\text {st }}$ century. Through the Internet, users are able to structure, store and process human communication.

Indeed, the effectiveness of collaborative learning over the Internet has been confirmed by various studies. It is found that students' levels of involvement and incentive to learn have increased significantly with a wider and more complete understanding of the subject knowledge (Lee \& Chen, 2000; Nagai et al, 2000; Su, Chen \& Tsai, 2000). Interaction among learners is fostered as communication via the web is simple and convenient when addressing to multiple users, and it is also time and space independent when compared to other means of communication. In addition, the Web stores messages on-line so that users can respond at their discretion, refer to previous exchanges and keep a record during the course of interaction easily. As a result, learners from different background and disperse locations can share their personal and team experience and pool their ideas to solve problems in the learning process.

Learners especially appreciated having a discussion forum as an avenue for communication when they were having their teaching practice at schools $(\mathrm{Ng}, 2001)$. Besides, learning efficiency (capabilities of integration and deduction) of Internet-based collaborative learning was found to be superior to Internet- 
$\mathrm{Ng} \& \mathrm{Ma}$

based traditional learning (Wang, Tzeng \& Chen, 2000; Chou \& Sun, 1995) when students were required to demonstrate and explain the contents and knowledge that they had learnt. Through this articulation process, old and new knowledge was integrated and new knowledge could be expended to other applications.

Peer assessment is another form of collaborative learning which encourages deep learning (Davies, 1999; Brindley \& Scoffield, 1998). Davies (2000) summarized the merits of on-line peer assessment which enabled learners to: (1) see how others work and identify good practice, (2) use other's work as a benchmark to judge their own understanding and ability, and (3) look at the work that they themselves produce from a marker's point of view and be more self-critical. The speed of the return of the marks and written comments were highlighted as a great benefit of the system as well.

To further explore the feasibility and efficiency of Web-based collaborative learning, more systematical researches have to be conducted. The following sections describe a learning model and implementation strategy of using the NextEd System to promote interaction and collaboration among learners and between learners and educators beyond the normal face-to-face classroom settings.

\section{A Model of Investigation}

Creating and maintaining truly committed cooperative groups are far from easy. The basic components of

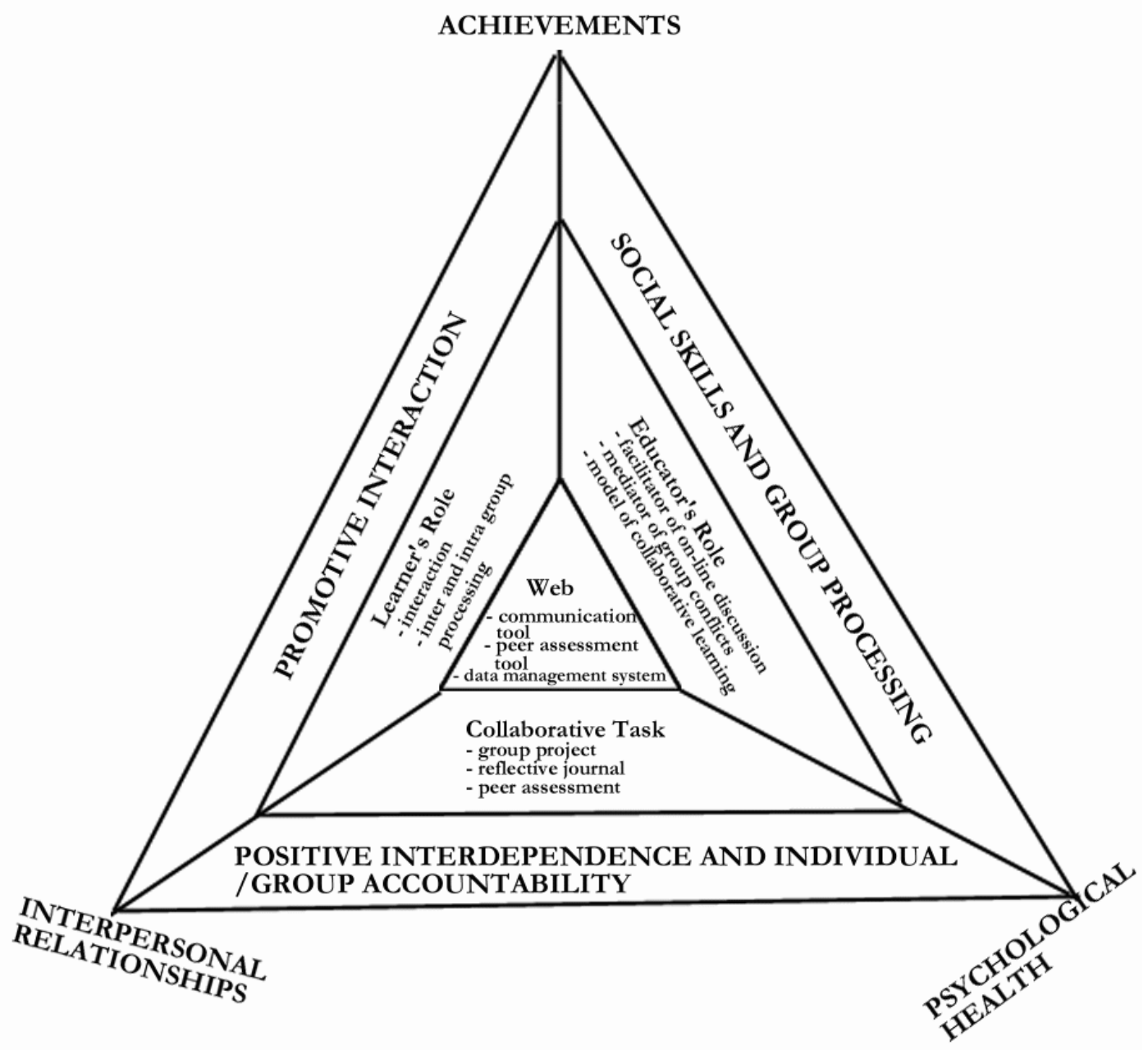

Figure 1 - An innovative model to foster collaborative learning via the Web 
effective cooperative efforts are positive interdependence, face-to-face promotive interaction, individual and group accountability, appropriate use of social skills, and group processing (Johnson, Johnson \& Smith, 1991). We plan to conduct a study to examine if the Web can foster collaborative learning by studying how learners interact within a group and with other group members. Learners studying year one at Bachelor of Education (Secondary) participated in this research.

With reference to the guidelines suggested by Johnson, Johnson and Smith (1991, p. 5:4), a model of investigation has been developed and is shown in Figure 1.

The design of the study is as follows:

Learners' role - Collaborative learning stresses that learners play a major role in all learning activities independently. All learners are to experience collaborative learning as an integral part of the course and a computerized peer assessment system as part of the assessment process.

Communication tool - the NextEd system provides both synchronous and asynchronous communication tools. Asynchronous tools include discussion forums, e-mails and newsgroups whilst chat room is a synchronous tool which provides users instant communication without delay. Learners can choose an appropriate way to participate in online discussion.

Collaborative task - learners will be asked to perform group projects which encompass more areas than intellective tasks. Learners are encouraged to coordinate on-line meetings via the group chat room which is synchronous and allows instantaneous interaction. It is expected learners will have frequent communication among group members.

Peer assessment - each group will also learn collaboratively with other groups by assessing other groups' work at the end of a semester so that a broader range of objective feedback and marks rather than subjective feedback from the educator could be obtained. The learners' social skills, creativity, critical thinking ability will also be fostered. It is apparent that the critical peer assessments lead to a greater selfawareness of their own abilities and performances which are especially important to student teachers.

Grouping - learners are assigned heterogeneously as research showed that heterogeneous groups outperformed homogeneous groups in creativity and decision-making tasks (Lee \& Chen, 2000). This is because heternoenenus orouns enahle oroun memhers with different characteristics and thinking natterns to sun-

Figure 1 - An innovative model to foster collaborative learning via the Web

Educator's role - learning occurs as individuals exercise, verify, solidify, improve their mental models through discussion and sharing and create new knowledge by interacting with other people. The educator's role is therefore to facilitate and to model collaborative learning with learners by participating in various learning and assessment activities.

\section{Implementation Plan}

\section{Figure 1 - An innovative model to foster collaborative learning via the Web}

Educator will develop learners' ability to work within the Web-based collaborative learning system and equip them with basic interpersonal and group skills at the beginning of a semester. Learners are required to understand the requirements of collaborative tasks during the learning process and for assessment. During the implementation, the educator will monitor the progress of each group and to give frequent on-line feedback to learners' discussions and meetings to mold the norms of sharing within groups. The procedures of implementing this innovative assessment are listed as follows: 


\section{Collaborative Learning Process}

Learners are required to divide the group project among group members so that each of them will carry out literature search over the Internet and then read, analyze, organize, and perhaps experiment with their materials by themselves initially. They will establish their own learning concepts and share what they have learnt via on-line discussion with their group members to form a holistic view when completing the project to maximize the group's goals. They are further required to reflect critically the progress of the group and to suggest methods and strategies to improve the group's effectiveness by writing a bi-weekly reflection journal and put it on the Web. The group will share each other's reflection and come up with an improved course of actions.

\section{Peer Assessment}

Apart from using the Web for learning, participants are required to perform peer assessment at the end of a semester making use of the convenience of the Web. Learners are to be briefed on the benefit of peer assessment to reduce any negative preconceived ideas they may have concerning this method of assessment. Learners will develop a checklist of criteria for assessment which is negotiable between the educator and learners. The criteria will be displayed onto the module web page for easy reference during the course of module delivery.

Learners utilize the on-line system to conduct the peer assessment either anonymously or nonanonymously within two weeks after submission of the project at their own time. Learners can access peer's feedback and in case of peer conflict concerning the comments and marks allocated, they have to justify the case and see if they can concur with each other's point of view within a week. The educator will play the mediator's role in case of unresolved conflicts.

\section{Data Collection Methods}

The data will be collected from two means. Quantitative information will be collected when participants post messages. The number of posted messages in the discussion board and usage of the chat room will be recorded. Similarly, the number of messages sent via e-mail will also be tracked. The quantitative data will be analyzed to examine if there is any relationship between the number of messages posted, number of chats held and the e-mail messages sent with the final assessment grades.

Qualitative information will be gathered by conducting focus group meetings and reading their reflective journals. The aim of the meetings is to have an in-depth understanding of participants' views on the effectiveness of collaborative learning via the Web in terms of learning efficiency and effectiveness, establishment of interpersonal relationships and state of psychological health. Participants will be encouraged to give suggestions on improving this innovative learning pedagogy and all the meetings will be taperecorded. The merits and shortcomings of the group project will be reflected in the bi-weekly journals which aim to provide concrete evidences of the collaborative efforts and areas which have been improved as a result of the group interaction.

\section{Conclusion}

Numerous research literatures have indicated the merits of collaborative learning. We have drawn the elements of collaborative learning from research findings and come up with a new model to be implemented for our learners in the coming semester. The Web provides a convenient and flexible avenue for on-line discussions and peer assessments which should be able to cultivate learners' positive attitude towards sharing. The evidence will be gathered through quantitative and qualitative means. With experiential learning, we believe our learners will be equipped with critical thinking, collaborative skills, and creativity which enable them to contribute successfully in an information age. 


\section{References}

Brindley, C., \& Scoffield, S. (1998). Peer assessment in undergraduate programmes, Teaching in higher education, 3 (1), 7989.

Brown, A. L. (1992). Design Experiments: Theoretical and Methodological Challenges in Creating Complex Interventions in Classroom Settings, Journal of the Learning Sciences, 2 (2) 141-178.

Chen, A. Y. (1993). Experienced and student teachers' reflection on classroom practice. Educational Research and Perspectives, 20 (1), 46-71.

Chou, C., \& Sun, C. T. (1995). Collaborative CAI by multimedia on the Internet. Teaching Information and Multimedia, 21, 13-21.

Davies, P. (2000). Computerized peer assessment. Innovations in Education and Training International 2000, 37(4), 34655.

Davies, P. (1999). Learning through assessment, OLAL on-line assessment and Learning, $3^{\text {rd }}$ CAA Conference Proceedings, Flexible Learning Initiative, 75-78.

Education Commission (2000). Learning for Life, Learning through Life - Reform Proposals for the Education System in Hong Kong. Hong Kong: Government Printer.

Johnson, D. W., Johnson, R., \& Smith, K. (1991). Active learning: Cooperative in the college classroom. Edina, MN: Interaction Book Company.

Johnson, D. W., \& Johnson, R. (1989). Cooperation and competition: Theory and research. Edina, MN: Interaction Book Company.

Johnson, D. W., \& Johnson, F. (1997). Joining together: Group theory and group skills (6 ${ }^{\text {th }}$ ed.). Boston: Allyn \& Bacon.

Johnson, D. W., \& Johnson, R. T. (1999). Learning together and alone: Cooperative, competitive and individualistic learning ( $5^{\text {th }}$ ed.). Boston: Allyn \& Bacon.

Johnson, D. W., \& Norem-Hebeisen (1981). Relationships between cooperative, competitive, and individualistic attitudes and differentiated aspects of self-esteem. Journal of Personality, 49, 415-426.

Lave, J., \& Wenger, E. (1991). Situated Learning: Legitimate Peripheral Participation. Cambridge University Press, New York.

Lee, Y. H., \& Chen, N. S. (2000). Group composition methods for cooperative learning in web-based instructional systems. Proceedings of The $8^{\text {th }}$ International Conference on Computers in Education/International Conference on Computer-Assisted Instruction 2000, 1538-1538.

Nagai, M., Okabe, Y., Nagata, J., \& Akahori, K. (2000). A study on the effectiveness of web-based collaborative learning system on school mathematics: Through a practice of three junior high schools. Proceedings of The $8^{\text {th }}$ International Conference on Computers in Education/International Conference on Computer-Assisted Instruction 2000, 279-283.

Ng, E. M. W. (2001). Fostering Self-directed and Collaborative Learning using Electronic Discussion Forum, Proceedings of The 9th International Conference on Computers in Education/SchoolNet2001, 531-534.

Scardamalia, M., \& Bereiter, C. (1996). Engaging Students in a Knowledge Society. Educational Leadership, 54(3) 6-11.

Slavin, R. E. (1996). Research on cooperative learning and achievement: What we know, what we need to know. Contemporary Educational Psychology, 21, 43-69.

Su, J., Chen, W., Chen, F., \& Tsai, Y. (2000). The project-based cooperative learning on Internet - A case study on Geology Education. Proceedings of The $8^{\text {th }}$ International Conference on Computers in Education/International Conference on Computer-Assisted Instruction 2000, 303-308.

Wang, W., Tzeng, Y., \& Chen, Y. (2000). A comparative study of applying Internet on cooperative traditional learning. Proceedings of The ${ }^{\text {th }}$ International Conference on Computers in Education/International Conference on ComputerAssisted Instruction 2000, 207-214. 


\section{Biographies}

\section{Eugenia M. W. Ng}

Eugenia M.W. Ng is the Deputy Head of Department of Information and Applied Technology, the Hong Kong Institute of Education. She is also the programme coordinator of Postgraduate Diploma in Education which is a two-year part-time initial teacher education programme designed for untrained graduate teachers who have taught business, design and technology related subjects. She is responsible for teaching information technology modules, ranging from sub-degree to post-graduate diploma level. She is interested in various research areas and has had over forty articles published in conference proceedings, journals and as book chapters apart from being a research investigator of many internal and external funded projects. During her limited leisure time, she enjoys swimming, travelling and playing badminton.

\section{Ada W. W. Ma}

Miss Ada MA is a lecturer from the Hong Kong Institute of Education. She is currently teaching in the Home Economics Section of the Department of Information and Applied Technology. Before joining the HKIEd in 1994, she had been working as a Home Economics teacher in secondary school; and a part-time lecturer in adult education center with focuses on textiles. Miss Ada Ma's research interests are: Gender Issues, Curriculum Innovations, Textile Education, as well as Web-based Learning. 